\title{
Manganese-Enhanced cardiac MRI (MEMRI) tracks long-term in vivo survival and restorative benefit of transplanted human Amnion-Derived Mesenchymal Stem Cells (hAMSC) after porcine ischemia-reperfusion injury
}

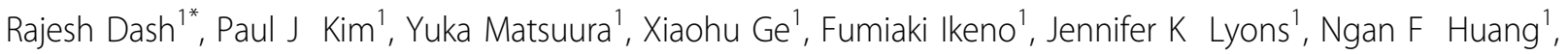 \\ Scott Metzler ${ }^{4}$, Patricia Nguyen ${ }^{1}$, Shahriar Heidary' ${ }^{1}$ Marie-Claude Parent ${ }^{1}$, Tomoaki Yamamoto ${ }^{1}$, John Cooke ${ }^{1}$, \\ Pilar Ruiz-Lozano ${ }^{4}$, Robert C Robbins ${ }^{2}$, Joseph C Wu ${ }^{1,3}$, Michael V McConnell ${ }^{1,5}$, Alan Yeung ${ }^{1}$, Phillip Harnish ${ }^{6}$, \\ Phillip C Yang ${ }^{1}$
}

From 16th Annual SCMR Scientific Sessions

San Francisco, CA, USA. 31 January - 3 February 2013

\section{Background}

It is unclear whether transplanted stem cells, despite their functional benefits, survive and engraft in the heart following transplantation. hAMSCs exhibit cell surface markers of immunomodulation (HLA-DR -, HLA-G +, CD59 +) that may enhance survival after transplantation. To investigate the viability of hAMSCs in vivo, we used a MEMRI contrast agent, EVP-1001-1 (Eagle Vision Pharmaceuticals, Inc) in a porcine ischemia-reperfusion (IR) injury model. EVP-1001-1 specifically enters live cells via L-type Ca2+ channels. Following EVP-1001-1 injection, MEMRI delineates the infarct zones through T1 signal loss. EVP-1001-1 also produces increased T1 signal in isolated hAMSCs.

\section{Methods}

Seven adult farm pigs underwent 60 min LAD coronary IR. One week post-IR, pigs hearts were injected with either hAMSCs $(\sim 80$ million cells/heart, $\mathrm{n}=4)$ or normal saline $(\mathrm{NS}, \mathrm{n}=3$ ) into $\sim 8$ peri-infarct and infarct zones, by intraventricular catheter injection (Biocardia, Inc.). Cardiac MRI (CMR) was performed serially to assess ejection fraction (EF\%), infarct \% by delayed gadolinium Enhancement MRI (DEMRI), and myocardial viability \% (MEMRI). (DEMRI \& MEMRI: GE 3T Signa Excite HD: FGRE-irP:
RT $4.7 \mathrm{~ms}$, TE $1.3 \mathrm{~ms}$, FOV 30, TI 200-400 ms, FA 10, ST $10 \mathrm{~mm}, 222 \times 192)$.

\section{Results}

hAMSC and NS EFs were similar at baseline $(57 \pm 4 \%, \mathrm{n}=5)$ and 1 wk post-IR $(24 \pm 6 \%)$. However, hAMSC injection improved EFs at 1, 2, \& 3wks post-hAMSC delivery, compared to NS-injected swine (Fig 1A). A possible mechanism for the improvement was increased peri-infarct viability. In support of this, MEMRI defect (infarct) volume decreased from $\mathrm{d} 7$ to $\mathrm{d} 21$ post-IR in hAMSC hearts $(60 \pm 12 \%$ reduction, $n=3)$ more than in NS hearts ( $38 \pm 18 \%$ reduction; Fig 1 F,G). MEMRI also identified foci of high contrast-to-noise ratio (CNR) within infarct zones in hAMSC hearts (hAMSC: $8.6 \pm 1.4^{*}$; NS: $4.9 \pm 0.8, \mathrm{n}=3$, " $\mathrm{p}<0.05$ Fig 1D,1E), suggesting increased EVP-1001-1 uptake by live hAMSCs within the infarct zone. This signal also increased from d10 to d17. In two swine, $20 \%$ of the hAMSCs were transduced with a HSV-tk PET reporter gene, and cardiac PET imaging confirmed co-localizing PET and MEMRI signals (Fig $1 \mathrm{H})$, indicating live stem cell populations (Fig 1I). Human anti-mitochondrial Ab immunostaining revealed viable hAMSC cell clusters in infarct zones 38 days post-transplantation.

${ }^{1}$ Medicine, Stanford University, Stanford, CA, USA

Full list of author information is available at the end of the article

(c) 2013 Dash et al; licensee BioMed Central Ltd. This is an Open Access article distributed under the terms of the Creative Commons Attribution License (http://creativecommons.org/licenses/by/2.0), which permits unrestricted use, distribution, and reproduction in any medium, provided the original work is properly cited. 


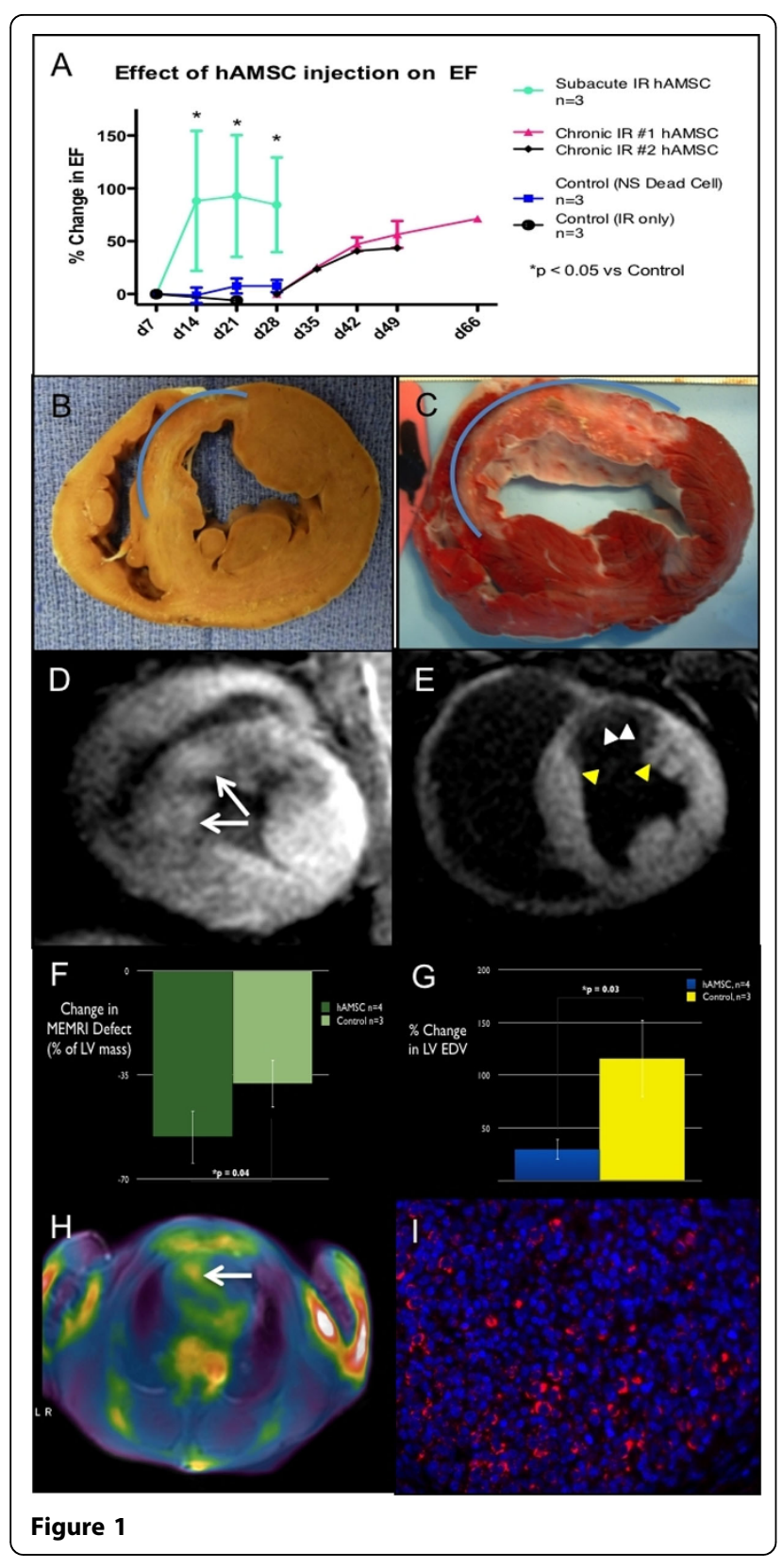

\section{Conclusions}

These results demonstrate that hAMSC delivery in a porcine IR model improves systolic function compared to control. The mechanism for this functional restoration may be due to improved peri-infarct viability by salvage of the injured cardiomyocytes. High MEMRI CNR within the infarct zone was associated with positive cardiac PET signal as well as hNA staining, indicating live hAMSC populations nearly 6 weeks after cell delivery. Moreover, MEMRI allows for non-invasive assessment of myocardial viability and tracking of stem cell survival in vivo, without any need for genetic pre-modification of the transplanted stem cells.

\section{Funding}

NIH R01 (PY).

NIH, NHLBI K08 (RD).

\section{Author details}

${ }^{1}$ Medicine, Stanford University, Stanford, CA, USA. ${ }^{2}$ Cardiac Surgery, Stanford University, Stanford, CA, USA. ${ }^{3}$ Radiology, Stanford University, Stanford, CA, USA. ${ }^{4}$ Pediatrics, Stanford University, Stanford, CA, USA. ${ }^{5}$ Engineering, Stanford University, Stanford, CA, USA. ${ }^{6}$ Eagle Vision Pharmaceutical Corp. Downington, PA, USA.

Published: 30 January 2013

doi:10.1186/1532-429X-15-S1-0106

Cite this article as: Dash et al:: Manganese-Enhanced cardiac MRI (MEMRI) tracks long-term in vivo survival and restorative benefit of transplanted human Amnion-Derived Mesenchymal Stem Cells (hAMSC) after porcine ischemia-reperfusion injury. Journal of Cardiovascular Magnetic Resonance 2013 15(Suppl 1):O106.

\section{Submit your next manuscript to BioMed Central} and take full advantage of:

- Convenient online submission

- Thorough peer review

- No space constraints or color figure charges

- Immediate publication on acceptance

- Inclusion in PubMed, CAS, Scopus and Google Scholar

- Research which is freely available for redistribution 